\title{
Comparison of Risk of Ovarian Malignancy Algorithm and cancer antigen 125 to discriminate between benign ovarian tumor and early-stage ovarian cancer according to imaging tumor subtypes
}

\author{
YOUNG-JAE LEE, YONG-MAN KIM, JI-SIK KANG, SO-HYUN NAM, DAE-YEON KIM and YOUNG-TAK KIM
}

\author{
Department of Obstetrics and Gynecology, University of Ulsan College of Medicine, \\ Asan Medical Center, Seoul 05505, Republic of Korea
}

Received August 25, 2019; Accepted April 1, 2020

DOI: $10.3892 /$ ol.2020.11629

\begin{abstract}
The present study aimed to compare the accuracy of the Risk of Ovarian Malignancy Algorithm (ROMA) and cancer antigen (CA)125 to discriminate between benign ovarian tumors and early-stage ovarian cancer according to imaging tumor subtypes associated with post-operative histopathological findings. A total of 1,207 patients who were assessed using the ROMA test due to suspected early-stage ovarian cancer and underwent surgery at Asan Medical Center (Seoul, Korea) between September 2014 and March 2018 were identified. A total of 981 patients who met the inclusion criteria were included in the retrospective analysis. Among the 981 subjects, 816 had benign tumors, 90 had malignant tumors and 75 had borderline tumors. Of the patients diagnosed with ovarian cancer or borderline tumor, $47.3 \%$ were judged as high-risk by the ROMA test and 58.2\% had CA125 levels of $>35 \mathrm{U} / \mathrm{ml}$. The specificity and accuracy of ROMA were higher compared with those of CA125 in pre-menopausal females. However, the superiority of the ROMA test in the identification of malignant ovarian tumors compared with CA125 was only observed in patients with endometriotic-type tumors but not in any of the other tumor subtypes. In the endometriotic type of ovarian tumor, the superiority of the ROMA test compared to CA125 was confirmed in triage of ovarian tumor. However, the sensitivity and specificity of ROMA and CA125 were similar for the other tumor types. Therefore, future development of
\end{abstract}

Correspondence to: Dr Yong-Man Kim, Department of Obstetrics and Gynecology, University of Ulsan College of Medicine, Asan Medical Center, 88 Olympic Road, Songpa, Seoul 05505, Republic of Korea

E-mail: amcymkim@gmail.com

Abbreviations: ROMA, Risk of Ovarian Malignancy Algorithm; CA125, cancer antigen 125; EOC, epithelial ovarian cancer; HE4, human epididymis protein 4

Key words: diagnostic techniques, ovarian cancer, cancer antigen 125 , biomarkers, epididymis better tumor-specific biomarkers for triage of ovarian tumor is required.

\section{Introduction}

According to cancer statistics reported in the United States in 2016, ovarian cancer is the leading cause of gynecological malignancy-associated mortality and $\sim 70 \%$ of patients are diagnosed at an advanced stage (1). Therefore, it is important to distinguish benign ovarian masses from early-stage malignant ovarian tumors to decide whether to operate, select the method of operation and to prevent cancer progression.

Cancer antigen (CA)125 is currently used as a conventional marker for epithelial ovarian cancer (EOC) (2). However, the serum CA125 expression levels are frequently increased and false-positive results may be obtained for certain benign uterine tumors and medical conditions, including leiomyomas, adenomyosis, infection, liver cirrhosis, pelvic endometriosis and pregnancy $(3,4)$. Serum CA125 expression levels are frequently in the normal range in early-stage invasive ovarian cancer (5). Therefore, CA125 is not recommended for the discrimination of ovarian tumors due to low specificity. Previously, it was demonstrated that human epididymis protein 4 (HE4) was involved in the neoplastic processes of EOC and HE4 has been used to overcome the aforementioned limitations in the discrimination of ovarian tumors $(6,7)$. HE4 expression levels are increased in certain ovarian cancers and it has the advantage of not being affected by physiological conditions, as is the case with CA125 $(8,9)$. Serum HE4 expression levels are not affected by the menstrual cycle, hormonal treatment and endometriosis, but expression levels may increase with age and smoking $(10,11)$. Therefore, the Risk of Ovarian Malignancy Algorithm (ROMA) test was developed using CA125, HE4 and menopausal status. The algorithm test is currently used for discriminating between benign and early-stage malignant ovarian tumors $(12,13)$.

Studies on the efficacy of the ROMA test have provided inconsistent results due to the different distribution of tumor subtypes in the patient population in each study. The expression levels of HE4 in tumors depend on the histological subtype. Drapkin et al (14) demonstrated that $100 \%$ of endometrioid and $93 \%$ of serous EOCs expressed HE4; however, only $50 \%$ of clear-cell carcinomas and no mucinous tumors 
were HE4-positive (14). However, no previous study has evaluated the efficacy of the ROMA test by tumor subtype and the majority of previous studies have only focused on the fact that ROMA is more useful in identifying endometriosis compared with CA125 (15-18). In addition, these studies have included several incidences of hydrosalpinx, paratubal cysts, inclusion cysts and advanced ovarian cancer that may be distinguished from each other using ultrasonography, as well as functional cysts that spontaneously disappeared in the follow-up period.

The present study investigated the efficacy of the ROMA test in comparison with CA125 as a tool for discriminating between benign and early-stage ovarian cancer according to imaging tumor subtypes associated with post-operative histopathological findings.

\section{Materials and methods}

Patients. After obtaining approval from The Institutional Review Board at the Asan Medical Center (Seoul, Republic of Korea; approval no. 2019-0616), the medical records of patients who underwent the ROMA test due to suspicion of early-stage ovarian cancer and were subjected to surgery at Asan Medical Center (Seoul, Republic of Korea) between September 2014 and March 2018 were retrospectively reviewed. The clinicopathological data were collected, including age, menopausal status, pre-operative results regarding CA125 and the ROMA test, results of imaging analysis (tumor size and volume), histological subtype and International Federation of Gynecology and Obstetrics stage (19) in malignant cases.

Only patients with histologically-confirmed diagnosis after surgery were included in the analysis. The patients were pathologically diagnosed by topography of the ovarian structure as the major differentiation point and additional immunostaining was performed when detailed discrimination or origin confirmation was required. Patients with advanced ovarian cancer with ascites and peritoneal carcinomatosis that were sufficiently predictable by sonography or abdominopelvic computed tomography (APCT) prior to surgery were excluded. Patients with only hydrosalpinx or paratubal cyst, inclusion cysts by pelvic adhesion and inflammatory lesions were excluded from the analysis, as these cases should have been excluded from suspicion of ovarian cancer by pre-operative evaluation with imaging or inflammatory tests. When ovarian masses were bilateral, they were included in the analysis if they were of the same subtype and excluded if they were different subtypes, as the subtype that affected the discrimination was not known in the present study and this may serve as a confounder. The presence of two or more tumor subtypes in one ovary were also excluded from the analysis, as it was not known which tumor subtype affected the blood test. Patients were excluded if there were $>3$ months between the operation and the blood test. Patients diagnosed with ovarian masses during pregnancy were excluded due to changes in the CA125 level following the gestation period. Patients with end-stage renal disease, diabetic nephropathy, nephrotic syndrome, renal cancer or urosepsis were excluded due to the possibility of serum HE4 levels being abnormally high due to decreased elimination or increased production from the damaged renal tubules (17). Patients who were diagnosed with other malignancies within 5 years were excluded as it was not possible to estimate the degree of the effect from primary site carcinoma. Patients with transient cell carcinoma, undifferentiated carcinoma, squamous cell carcinoma and mixed Müllerian malignant tumor were excluded from the analysis due to the rarity of such cases.

Laboratory methods. The present study used the ARCHITECT CA125 II assay (cat. no. 2P45) and the ARCHITECT HE4 assay (cat. no. 2P54; Abbott Pharmaceutical Co. Ltd.) for the quantitative determination of CA125 and HE4 expression levels (20). These were two-step immunoassays that used the chemiluminescent microparticle immunoassay technology (Abbott Pharmaceutical Co., Ltd.), which were performed according to the manufacturer's protocol. The cut-off value was $35.0 \mathrm{U} / \mathrm{ml}$ for CA125 and $70 \mathrm{pmol} / \mathrm{ml}$ for HE4. The expression levels of these markers were defined as normal when lower than the cut-off value. Patients were then stratified into low- or high-risk groups based on laboratory methods for calculating the ROMA score and menopausal status. Predictive index (PI) and predicted probability were calculated using the following algorithms proposed by Moore et al (11): Pre-menopausal PI $=-12.0+2.38 \mathrm{x}$ LN (natural log) (HE4) +0.0626x LN(CA125); Post-menopausal $\mathrm{PI}=-8.09+1.04 \mathrm{x}$ LN(HE4) +0.7320x LN(CA125); Predicted probability $(\mathrm{ROMA}, \%)=\exp (\mathrm{PI}) /[1+\exp (\mathrm{PI})] \times 100$.

The cut-off value for ROMA was 7.4 for pre-menopausal females and 25.3 for post-menopausal females. Regarding the menopausal status, post-menopausal was defined as 1 year or more after cessation of menstrual bleeding. For patients who underwent hysterectomy prior to menopause, an age of 50 years or above was defined as post-menopausal. The result of the blood tests (CA125 and ROMA test) were defined as true if it was within the normal range (below cut-off value) for benign tumors or above the normal range for malignant tumors.

Imaging study. For the imaging study, sonography or APCT were routinely performed as hospital practice. There were no definite criteria for the size or number of leiomyomas affecting the CA125 level. Therefore, one or more leiomyoma $>3 \mathrm{~cm}$ was considered positive for the presence of leiomyoma. All images were blindly interpreted by two radiologists at the Asan Medical Center (Seoul, Republic of Korea) and the total ovarian tumor volume was calculated.

Imaging subtypes of tumors. This classification system was specifically used for the present study. In this system, diseases that appear similar in image and are difficult to distinguish by image alone are grouped together. This group was subsequently used to compare and analyze the efficacy of CA125 and ROMA tests to identify malignant tumors. Accordingly, imaging subtypes of tumors were classified for analysis as associated with post-operative histological findings as follows: Serous cystadenoma, corpus luteal cyst, simple cyst, serous borderline tumor, serous adenocarcinoma were classified as 'serous type'; mucinous cystadenoma, mucinous borderline tumor and mucinous adenocarcinoma were classified as 'mucinous type'; endometriotic cyst, seromucinous borderline tumor, endometrioid adenocarcinoma and clear cell carcinoma were classified as 'endometriotic type'; and mature cystic teratoma, 
Table I. Characteristics of patients with ovarian tumors.

\begin{tabular}{lcccr}
\hline Parameter & Benign disease $(\mathrm{n}=816)$ & Borderline disease $(\mathrm{n}=75)$ & Ovarian cancer $(\mathrm{n}=90)$ & P-value \\
\hline Age (years) & $41.00(31.00-49.00)^{\mathrm{a}}$ & $41.00(30.50-54.00)^{\mathrm{b}}$ & $49.50(42.00-55.00)$ & $<0.001$ \\
Menopausal status & & & & \\
Pre- & $628(77.0)^{\mathrm{a}}$ & $51(68.0)$ & $50(55.6)$ & $<0.001$ \\
Post- & $188(23.0)$ & $24(32.0)$ & $40(44.4)$ & $<0.001$ \\
CA125 $(\mathrm{U} / \mathrm{ml})$ & $24.00(14.00-57.10)^{\mathrm{a}}$ & $33.50(18.50-62.20)^{\mathrm{c}}$ & $61.50(25.60-238.82)$ & $<0.001$ \\
CA125 $>35 \mathrm{U} / \mathrm{ml}$ & $301(36.9)^{\mathrm{a}}$ & $35(46.7)$ & $61(67.8)$ & $<0.001$ \\
HE4 level $(\mathrm{pmol} / \mathrm{l})$ & $39.80(33.50-48.60)^{\mathrm{a}}$ & $45.00(35.15-52.90)^{\mathrm{a}}$ & $64.45(43.58-93.78)$ & $<0.001$ \\
ROMA high risk & $135(16.5)^{\mathrm{a}, \mathrm{d}}$ & $21(28.0)^{\mathrm{a}}$ & $57(63.3)$ & $<0.001$ \\
Tumor volume $\left(\mathrm{cm}^{3}\right)$ & $153.50(60.00-371.25)^{\mathrm{a}, \mathrm{e}}$ & $1,300.00(227.50-3,154.50)$ & $548.00(214.75-1,554.00)$ & $<0.001$
\end{tabular}

${ }^{\mathrm{a}} \mathrm{P}<0.001$ vs. ovarian cancer, ${ }^{\mathrm{b}} \mathrm{P}=0.003$ vs. ovarian cancer, ${ }^{\mathrm{C}} \mathrm{P}=0.001$ vs. ovarian cancer, ${ }^{\mathrm{d}} \mathrm{P}=0.006$ vs. borderline disease, ${ }^{\mathrm{e}} \mathrm{P}<0.001 \mathrm{vs}$. borderline disease. Values are expressed as n (\%) or median (interquartile range). CA125, cancer antigen 125; HE4, human epididymis protein 4; ROMA, Risk of Ovarian Malignancy Algorithm.

fibroma, Brenner tumor, germ cell tumor and sex-cord stromal cell tumor were classified as 'solid type'.

Statistical analysis. Associations between variable characteristics and ovarian tumors were assessed by Mann Whitney-U tests followed by Bonferroni's correction. Patient characteristics are presented as the median and interquartile range. Diagnostic performance of CA125 and ROMA was compared in patients with suspected ovarian cancer stratified by menopausal status, leiomyomas and adenomyosis. The sensitivity, specificity, positive predictive value (PPV), negative predictive value (NPV) and accuracy of the two methods were compared. CA125 and the ROMA test were analyzed using imaging of tumor subtype. For the analysis of discrepancies in the two prediction methods, McNemar's test was used to assess how the two measurements differed without considering the outcome data. The net reclassification index (NRI) indicated the extent to which the ROMA test improved prediction compared with CA125 using outcome data. Due to the fact that the ROMA test had different scales for pre-menopausal and post-menopausal patients, receiver operating characteristic (ROC) analysis was also performed for these groups. The P-values for comparing the two ROC curves were calculated using Delong's test for two associated ROC curves. For P-values subjected to Bonferroni correction, $\mathrm{P}>0.0167(0.05 / 3)$ was considered to indicate a statistically significant difference. For all other data, $\mathrm{P}<0.05$ was considered to indicate a statistically significant difference. All statistical analyses were performed using SPSS software version 21.0 (IBM Corp.).

\section{Results}

Patient characteristics. Among the 1,207 patients identified in the initial search, 981 met the inclusion criteria and were included in the retrospective analysis. Of these patients, $816(83.2 \%)$ were diagnosed with benign disease, 75 (7.6\%) with borderline disease and $90(9.2 \%)$ had cancer. All serous adenocarcinoma included in the study were of high grade. The characteristics of the patients are summarized in Table I. Patients who were diagnosed with ovarian cancer were older and more likely to be post-menopausal $(\mathrm{P}<0.001)$. Of the patients diagnosed with ovarian cancer, $63.3 \%$ were judged as being high-risk according to the ROMA test and $67.8 \%$ had CA125 levels of $>35 \mathrm{U} / \mathrm{ml}$. This sensitivity was further reduced by including patients with borderline tumors: A total of $47.3 \%$ (78/165) were judged as being high-risk using the ROMA test and 58.2\% (96/165) had CA125 levels of $>35 \mathrm{U} / \mathrm{ml}$. In the same patient group, a total of $65.5 \%$ were judged as being high-risk using the ROMA test and/or had CA125 levels of $>35 \mathrm{U} / \mathrm{ml}$ (Table I). The tumor volume was by far the largest among borderline tumors $(\mathrm{P}<0.001)$. Histology, stage, and degree of differentiation of ovarian tumors are summarized in Table II. One or more leiomyomas sized $>3 \mathrm{~cm}$ were detected in 119 patients $(12.1 \%)$, and adenomyosis was suspected in 118 patients $(12.0 \%)$ using imaging (data not shown).

Influence of menopausal status, leiomyoma and adenomyosis. Table III summarizes comparisons of the diagnostic performance of CA125 and ROMA in patients with suspected ovarian cancer stratified by menopausal status, leiomyomas and adenomyosis. The sensitivity of CA125 was higher compared with that of ROMA in pre-menopausal ( 0.584 vs. 0.455$)$ but not in post-menopausal females $(0.578$ vs. 0500$)$. The specificity (0.818 vs. 0.556$)$, PPV ( 0.288 vs. 0.175$)$ and accuracy (0.768 vs. $0.560)$ of ROMA were higher compared with those of CA125 in pre-menopausal but not in post-menopausal females. The specificity and accuracy of ROMA in all patients were higher compared with those of CA125, regardless of leiomyomas or adenomyosis; however, this difference was not observed in post-menopausal females. A possible explanation for these differences may be due to the fact that mostly endometriotic types are present in pre-menopausal females.

Efficacy according to imaging tumor subtype. Data on the efficacy of CA125 and ROMA according to tumor subtype are presented in Table IV. The subtypes of tumors were classified based on the post-operative histological findings. A total of 189 cases $(19.3 \%)$ were of the serous type, $196(20.0 \%)$ were mucinous, $346(35.3 \%)$ were endometriotic and $250(25.5 \%)$ were of the solid type. In the analysis by tumor subtype, the 
Table II. Histology, stage and degree of differentiation of ovarian tumors.

\begin{tabular}{|c|c|c|c|}
\hline Parameter & Benign disease $(n=816)$ & Borderline disease $(n=75)$ & Ovarian cancer $(n=90)$ \\
\hline \multicolumn{4}{|l|}{ Pathology } \\
\hline Serous cystadenoma & $67(8.2)$ & $0(0.0)$ & $0(0.0)$ \\
\hline Mucinous cystadenoma & $128(15.7)$ & $0(0.0)$ & $0(0.0)$ \\
\hline Endometriotic cyst & $304(37.3)$ & $0(0.0)$ & $0(0.0)$ \\
\hline Mature cystic teratoma & $177(21.7)$ & $0(0.0)$ & $0(0.0)$ \\
\hline Corpus luteal cyst & $37(4.5)$ & $0(0.0)$ & $0(0.0)$ \\
\hline Fibroma & $54(6.6)$ & $0(0.0)$ & $0(0.0)$ \\
\hline Simple cyst & $45(5.5)$ & $0(0.0)$ & $0(0.0)$ \\
\hline Brenner tumor & $4(0.5)$ & $0(0.0)$ & $0(0.0)$ \\
\hline Serous borderline tumor & $0(0.0)$ & $17(22.7)$ & $0(0.0)$ \\
\hline Mucinous borderline tumor & $0(0.0)$ & $48(64.0)$ & $0(0.0)$ \\
\hline Seromucinous borderline tumor & $0(0.0)$ & $10(13.3)$ & $0(0.0)$ \\
\hline High-grade serous adenocarcinoma & $0(0.0)$ & $0(0.0)$ & $23(25.6)$ \\
\hline Mucinous adenocarcinoma & $0(0.0)$ & $0(0.0)$ & $20(22.2)$ \\
\hline Endometrioid adenocarcinoma & $0(0.0)$ & $0(0.0)$ & $18(20.0)$ \\
\hline Clear cell carcinoma & $0(0.0)$ & $0(0.0)$ & 14 (15.6) \\
\hline Germ cell tumor & $0(0.0)$ & $0(0.0)$ & $6(6.7)$ \\
\hline Sex-cord stromal cell tumor & $0(0.0)$ & $0(0.0)$ & $9(10.0)$ \\
\hline \multicolumn{4}{|l|}{ FIGO stage } \\
\hline I & $0(0.0)$ & $74(98.7)$ & $67(74.4)$ \\
\hline II-III & $0(0.0)$ & $1(1.3)$ & $23(25.6)$ \\
\hline \multicolumn{4}{|l|}{ Degree of differentiation } \\
\hline Well-differentiated & $0(0.0)$ & $0(0.0)$ & $26(28.9)$ \\
\hline Moderately differentiated & $0(0.0)$ & $0(0.0)$ & $11(12.2)$ \\
\hline Poorly differentiated & $0(0.0)$ & $0(0.0)$ & $44(48.9)$ \\
\hline Unknown & $0(0.0)$ & $0(0.0)$ & $9(10.0)$ \\
\hline
\end{tabular}

FIGO, International Federation of Gynecology and Obstetrics.

ROMA test had better efficacy in terms of specificity $(0.753$ vs. 0.303$)$, PPV (0.257 vs. 0.120), NPV (0.935 vs. 0.876) and accuracy (0.737 vs. 0.350$)$ compared with CA125 in the endometriotic type and somewhat superior results in terms of specificity (0.881 vs. 0.791$)$ and accuracy (0.852 vs. 0.768$)$ in the solid type. In the serous and mucinous type, the efficacy of the ROMA test was not significantly different from that of CA125, while the sensitivity of CA125 in the serous type was higher compared with that of the ROMA test (0.950 vs. 0.750).

Analysis of discrepancies. Table $\mathrm{V}$ presents an analysis of discrepancies between the two prediction methods. McNemar's test was used to assess how the two measurements differed, without considering the outcome data. And the NRI indicated the extent to which the ROMA test improved prediction compared with CA125, using outcome data. A total of 276 patients $(28.1 \%)$ had discrepancies between the results of the two predictive methods. In a total of 151 cases of the endometriotic type, accounting for $>50 \%$ of these patients, CA125 levels were elevated but they were classified as low-risk by the ROMA test (McNemar's test $\mathrm{P}<0.001)$. These results demonstrated that the ROMA test provided superior prediction in the endometriotic type compared with CA125 (NRI=0.379). However, there was no significant difference between the results of the two predictive methods in the mucinous type. Furthermore, the NRI values compared with CA125 suggested that ROMA did not provide any improved prediction in the mucinous type (NRI=0.095) and solid type (NRI=0.089), and had a worse predictive ability in the serous type (NRI=-0.153).

ROC curves for ROMA test and CA125. Fig. 1 provides the ROC curves for each tumor type in pre-menopausal and post-menopausal females. The ROMA test had better predictive accuracy compared with CA125 in the overall ROC curve based on the analysis of pre-menopausal patients. However, in the analysis by tumor subtype, these comparative advantages were only observed in pre-menopausal cases of the endometriotic type, but not in the other tumor subtypes or post-menopausal females.

\section{Discussion}

All previous studies evaluating the ROMA test demonstrated and emphasized its superior specificity compared with that 
Table III. Predictive value of CA125 and ROMA in patients with suspected ovarian cancer stratified by menopausal status, leiomyomas and adenomyosis.

\begin{tabular}{|c|c|c|c|c|c|}
\hline Type & $\begin{array}{c}\text { Sensitivity } \\
(95 \% \mathrm{CI})\end{array}$ & $\begin{array}{l}\text { Specificity } \\
(95 \% \mathrm{CI})\end{array}$ & $\begin{array}{c}\text { PPV } \\
(95 \% \mathrm{CI})\end{array}$ & $\begin{array}{c}\text { NPV } \\
(95 \% \mathrm{CI})\end{array}$ & $\begin{array}{l}\text { Accuracy } \\
(95 \% \mathrm{CI})\end{array}$ \\
\hline \multicolumn{6}{|c|}{ Pre-menopause } \\
\hline CA125 & $\begin{array}{c}0.584 \\
(0.482-0.681)\end{array}$ & $\begin{array}{c}0.556 \\
(0.516-0.595)\end{array}$ & $\begin{array}{c}0.175 \\
(0.136-0.219)\end{array}$ & $\begin{array}{c}0.893 \\
(0.858-0.921)\end{array}$ & $\begin{array}{c}0.56 \\
(0.523-0.596)\end{array}$ \\
\hline ROMA & $\begin{array}{c}0.455 \\
(0.356-0.558)\end{array}$ & $\begin{array}{c}0.818 \\
(0.786-0.848)\end{array}$ & $\begin{array}{c}0.288 \\
(0.219-0.364)\end{array}$ & $\begin{array}{c}0.903 \\
(0.876-0.926)\end{array}$ & $\begin{array}{c}0.768 \\
(0.736-0.798)\end{array}$ \\
\hline \multicolumn{6}{|c|}{ Post-menopause } \\
\hline CA125 & $\begin{array}{c}0.578 \\
(0.448-0.701)\end{array}$ & $\begin{array}{c}0.883 \\
(0.828-0.925)\end{array}$ & $\begin{array}{c}0.627 \\
(0.491-0.75)\end{array}$ & $\begin{array}{c}0.86 \\
(0.803-0.906)\end{array}$ & $\begin{array}{c}0.806 \\
(0.751-0.853)\end{array}$ \\
\hline ROMA & $\begin{array}{c}0.5 \\
(0.372-0.628)\end{array}$ & $\begin{array}{c}0.888 \\
(0.834-0.93)\end{array}$ & $\begin{array}{c}0.604 \\
(0.46-0.735)\end{array}$ & $\begin{array}{c}0.839 \\
(0.781-0.887)\end{array}$ & $\begin{array}{c}0.79 \\
(0.734-0.838)\end{array}$ \\
\hline \multicolumn{6}{|c|}{ Leiomyoma - } \\
\hline CA125 & $\begin{array}{c}0.573 \\
(0.49-0.654)\end{array}$ & $\begin{array}{c}0.659 \\
(0.623-0.694)\end{array}$ & $\begin{array}{c}0.261 \\
(0.215-0.312)\end{array}$ & $\begin{array}{c}0.88 \\
(0.849-0.906)\end{array}$ & $\begin{array}{c}0.644 \\
(0.611-0.676)\end{array}$ \\
\hline ROMA & $\begin{array}{c}0.447 \\
(0.366-0.53)\end{array}$ & $\begin{array}{c}0.857 \\
(0.829-0.882)\end{array}$ & $\begin{array}{c}0.396 \\
(0.322-0.474)\end{array}$ & $\begin{array}{c}0.88 \\
(0.854-0.903)\end{array}$ & $\begin{array}{c}0.785 \\
(0.756-0.812)\end{array}$ \\
\hline \multicolumn{6}{|c|}{ Leiomyoma + } \\
\hline CA125 & $\begin{array}{c}0.667 \\
(0.384-0.882)\end{array}$ & $\begin{array}{c}0.442 \\
(0.345-0.543)\end{array}$ & $\begin{array}{c}0.147 \\
(0.073-0.254)\end{array}$ & $\begin{array}{c}0.902 \\
(0.786-0.967)\end{array}$ & $\begin{array}{c}0.471 \\
(0.378-0.564)\end{array}$ \\
\hline ROMA & $\begin{array}{c}0.733 \\
(0.449-0.922)\end{array}$ & $\begin{array}{c}0.683 \\
(0.584-0.771)\end{array}$ & $\begin{array}{c}0.25 \\
(0.132-0.403)\end{array}$ & $\begin{array}{c}0.947 \\
(0.869-0.985)\end{array}$ & $\begin{array}{c}0.689 \\
(0.598-0.771)\end{array}$ \\
\hline \multicolumn{6}{|c|}{ Adenomyosis - } \\
\hline CA125 & $\begin{array}{c}0.565 \\
(0.483-0.645)\end{array}$ & $\begin{array}{c}0.688 \\
(0.653-0.722)\end{array}$ & $\begin{array}{c}0.282 \\
(0.233-0.336)\end{array}$ & $\begin{array}{c}0.879 \\
(0.849-0.905)\end{array}$ & $\begin{array}{c}0.666 \\
(0.634-0.698)\end{array}$ \\
\hline ROMA & $\begin{array}{c}0.461 \\
(0.381-0.543)\end{array}$ & $\begin{array}{c}0.87 \\
(0.843-0.894)\end{array}$ & $\begin{array}{c}0.436 \\
(0.358-0.515)\end{array}$ & $\begin{array}{c}0.881 \\
(0.855-0.904)\end{array}$ & $\begin{array}{c}0.797 \\
(0.769-0.824)\end{array}$ \\
\hline \multicolumn{6}{|c|}{ Adenomyosis + } \\
\hline CA125 & $\begin{array}{c}0.818 \\
(0.482-0.977)\end{array}$ & $\begin{array}{c}0.252 \\
(0.173-0.346)\end{array}$ & $\begin{array}{c}0.101 \\
(0.047-0.183)\end{array}$ & $\begin{array}{c}0.931 \\
(0.772-0.992)\end{array}$ & $\begin{array}{c}0.305 \\
(0.224-0.397)\end{array}$ \\
\hline ROMA & $\begin{array}{c}0.636 \\
(0.308-0.891)\end{array}$ & $\begin{array}{c}0.598 \\
(0.499-0.692)\end{array}$ & $\begin{array}{c}0.14 \\
(0.058-0.267)\end{array}$ & $\begin{array}{c}0.941 \\
(0.856-0.984)\end{array}$ & $\begin{array}{c}0.602 \\
(0.507-0.691)\end{array}$ \\
\hline
\end{tabular}

PPV, positive predictive value; NPV, negative predictive value; CA125, cancer antigen 125; ROMA, Risk of Ovarian Malignancy Algorithm.

of the CA125 test. However, these studies did not separately analyze the histological subtypes of ovarian tumors (21-23). Although Kim et al (15) investigated the diagnostic performance of ROMA for ovarian cancer, two-thirds of the patients did not have ovarian tumors but had adenomyosis, leiomyomas, an endometrial pathology or ovarian tumors without biopsy. As mentioned above, the expression levels of HE4 in tumors vary depending on the histological subtype. Therefore, it is necessary to assess the expected degree of prediction accuracy of the ROMA test compared with that of CA125 in discriminating ovarian tumors for each tumor subtype. According to the results of the present study, the superiority of the ROMA test in the identification of malignant ovarian tumors compared with CA125 was observed only in pre-menopausal cases of the endometriotic type and comparative advantages were not observed in other tumor subtypes.
The specificity and accuracy of ROMA were higher compared with those of the CA125 test regardless of leiomyomas or adenomyosis in pre-menopausal females but not in post-menopausal females. This difference may be due to most cases of endometriosis being pre-menopausal females and ROMA being superior to CA125 in discriminating endometriotic type ovarian tumors. In the presence of leiomyomas and adenomyosis, the specificity and accuracy of CA125 and ROMA was decreased; however, the specificity and accuracy of CA125 were decreased compared with those of the ROMA test. This may be due to the inclusion of HE4, which is not affected by leiomyomas or adenomyosis.

According to a previous meta-analysis of five studies, ROMA had a sensitivity of 0.873 (95\% CI, 0.752-0.940) and a specificity of 0.855 (95\% CI, 0.719-0.932) (24). In the present study, the sensitivity of ROMA ( 0.455 in pre-menopausal vs. 0.500 in post-menopausal females) and CA125 (0.584 in 
Table IV. Predictive efficacy of CA125 and ROMA according to imaging tumor subtype.

\begin{tabular}{|c|c|c|c|c|c|}
\hline Type & $\begin{array}{l}\text { Sensitivity } \\
(95 \% \mathrm{CI})\end{array}$ & $\begin{array}{l}\text { Specificity } \\
(95 \% \text { CI) }\end{array}$ & $\begin{array}{c}\text { PPV } \\
(95 \% \mathrm{CI})\end{array}$ & $\begin{array}{c}\text { NPV } \\
(95 \% \mathrm{CI})\end{array}$ & $\begin{array}{l}\text { Accuracy } \\
(95 \% \text { CI) }\end{array}$ \\
\hline \multicolumn{6}{|c|}{ Serous $(n=189)$} \\
\hline CA125 & $\begin{array}{c}0.95 \\
(0.831-0.994)\end{array}$ & $\begin{array}{c}0.846 \\
(0.777-0.9)\end{array}$ & $\begin{array}{c}0.623 \\
(0.49-0.744)\end{array}$ & $\begin{array}{c}0.984 \\
(0.945-0.998)\end{array}$ & $\begin{array}{c}0.868 \\
(0.811-0.913)\end{array}$ \\
\hline ROMA & $\begin{array}{c}0.75 \\
(0.588-0.873)\end{array}$ & $\begin{array}{c}0.893 \\
(0.831-0.937)\end{array}$ & $\begin{array}{c}0.652 \\
(0.498-0.786)\end{array}$ & $\begin{array}{c}0.93 \\
(0.875-0.966)\end{array}$ & $\begin{array}{c}0.862 \\
(0.805-0.908)\end{array}$ \\
\hline \multicolumn{6}{|c|}{ Mucinous ( $n=196$ ) } \\
\hline CA125 & $\begin{array}{c}0.338 \\
(0.228-0.463)\end{array}$ & $\begin{array}{c}0.867 \\
(0.796-0.921)\end{array}$ & $\begin{array}{c}0.575 \\
(0.409-0.73)\end{array}$ & $\begin{array}{c}0.712 \\
(0.634-0.781)\end{array}$ & $\begin{array}{c}0.684 \\
(0.614-0.748)\end{array}$ \\
\hline ROMA & $\begin{array}{c}0.235 \\
(0.141-0.354)\end{array}$ & $\begin{array}{c}0.875 \\
(0.805-0.927)\end{array}$ & $\begin{array}{c}0.5 \\
(0.319-0.681)\end{array}$ & $\begin{array}{c}0.683 \\
(0.606-0.753)\end{array}$ & $\begin{array}{c}0.653 \\
(0.582-0.719)\end{array}$ \\
\hline \multicolumn{6}{|c|}{ Endometriotic $(\mathrm{n}=346)$} \\
\hline CA125 & $\begin{array}{c}0.69 \\
(0.529-0.824)\end{array}$ & $\begin{array}{c}0.303 \\
(0.251-0.358)\end{array}$ & $\begin{array}{c}0.12 \\
(0.082-0.168)\end{array}$ & $\begin{array}{c}0.876 \\
(0.798-0.932)\end{array}$ & $\begin{array}{c}0.35 \\
(0.299-0.403)\end{array}$ \\
\hline ROMA & $\begin{array}{c}0.619 \\
(0.456-0.764)\end{array}$ & $\begin{array}{c}0.753 \\
(0.701-0.801)\end{array}$ & $\begin{array}{c}0.257 \\
(0.176-0.354)\end{array}$ & $\begin{array}{c}0.935 \\
(0.896-0.962)\end{array}$ & $\begin{array}{c}0.737 \\
(0.687-0.783)\end{array}$ \\
\hline \multicolumn{6}{|c|}{ Solid $(n=250)$} \\
\hline CA125 & $\begin{array}{c}0.4 \\
(0.163-0.677)\end{array}$ & $\begin{array}{c}0.791 \\
(0.734-0.842)\end{array}$ & $\begin{array}{c}0.109 \\
(0.041-0.222)\end{array}$ & $\begin{array}{c}0.954 \\
(0.914-0.979)\end{array}$ & $\begin{array}{c}0.768 \\
(0.711-0.819)\end{array}$ \\
\hline ROMA & $\begin{array}{c}0.4 \\
(0.163-0.677)\end{array}$ & $\begin{array}{c}0.881 \\
(0.832-0.919)\end{array}$ & $\begin{array}{c}0.176 \\
(0.068-0.345)\end{array}$ & $\begin{array}{c}0.958 \\
(0.922-0.981)\end{array}$ & $\begin{array}{c}0.852 \\
(0.802-0.894)\end{array}$ \\
\hline
\end{tabular}

PPV, positive predictive value; NPV, negative predictive value; CA125, cancer antigen 125; ROMA, Risk of Ovarian Malignancy Algorithm.

Table V. Analysis of discrepancies between the CA125 and ROMA prediction methods.

\begin{tabular}{lrcccrr}
\hline Type & $\begin{array}{c}\text { CA125 and } \\
\text { ROMA low }\end{array}$ & $\begin{array}{c}\text { CA125 high and } \\
\text { ROMA low }\end{array}$ & $\begin{array}{c}\text { CA125 low and } \\
\text { ROMA high }\end{array}$ & $\begin{array}{c}\text { CA125 and } \\
\text { ROMA high }\end{array}$ & $\begin{array}{c}\text { McNemar's test } \\
\text { P-value }\end{array}$ & NRI \\
\hline Serous $(\mathrm{n}=189)$ & $116(61.4)$ & $27(14.3)$ & $12(6.3)$ & $34(18.0)$ & 0.025 & -0.153 \\
Mucinous $(\mathrm{n}=196)$ & $143(73.0)$ & $21(10.7)$ & $13(6.6)$ & $19(9.7)$ & 0.230 & -0.095 \\
Endometriotic $(\mathrm{n}=346)$ & $94(27.2)$ & $151(43.6)$ & $11(3.2)$ & $90(26.0)$ & $<0.001$ & 0.379 \\
Solid $(\mathrm{n}=250)$ & $185(74.0)$ & $31(12.4)$ & $10(4.0)$ & $24(9.6)$ & 0.002 & 0.089 \\
Total $(\mathrm{n}=981)$ & $538(54.8)$ & $230(23.4)$ & $46(4.7)$ & $167(17.0)$ & $<0.001$ & 0.094 \\
\hline
\end{tabular}

Values are expressed as n (\%). CA125, cancer antigen 125; ROMA, Risk of Ovarian Malignancy Algorithm; NRI, net reclassification index.

pre-menopausal vs. 0.578 in post-menopausal females) were lower compared with the previously reported results. This may be due to the present study including only histologically-confirmed patients after surgery, while advanced ovarian cancer or hydrosalpinx that were sufficiently predictable using imaging were excluded from the analysis. The inclusion of a number of patients with borderline tumors may also be the cause of the comparatively lower sensitivities obtained in the present study.

In clinical practice, gynecologists establish the prediction marker after determining the approximate tumor subtype and degree of doubt regarding malignancy using preoperative imaging. When determining the approximate tumor subtype through sonography or APCT, knowledge of the accuracy of the prediction marker for each tumor subtype makes it possible to select the test according to the expectation of each test. The present study compared the predictive value of CA125 and the ROMA test for identifying ovarian tumors according to tumor subtypes by imaging associated with post-operative histological findings. The imaging test performed in all patients to confirm the suspicion of leiomyomas or adenomyosis, which was reaffirmed to determine whether these factors affected the accuracy of the CA125 and ROMA tests. Previous studies on ROMA only focused on epithelial ovarian tumors and did not assess malignant germ cell tumors or epithelial borderline tumors (15-17). The present study evaluated the utility of prediction markers in more diverse tumors, including 75 borderline tumors and 15 germ cell or sex-cord stromal cell tumors. 
A
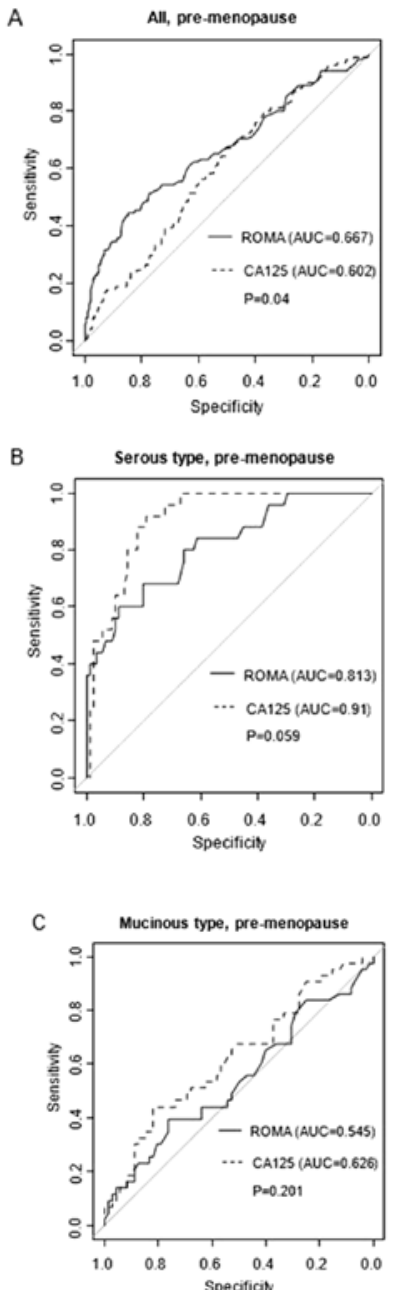

D
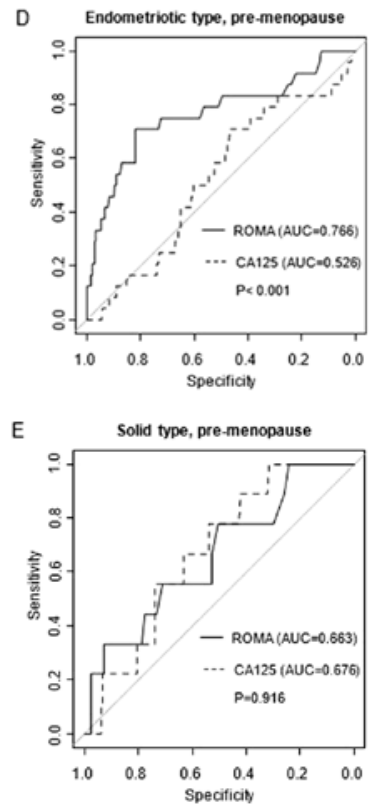

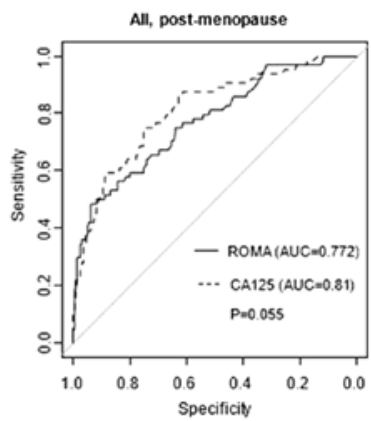

Serous type, post-menopause
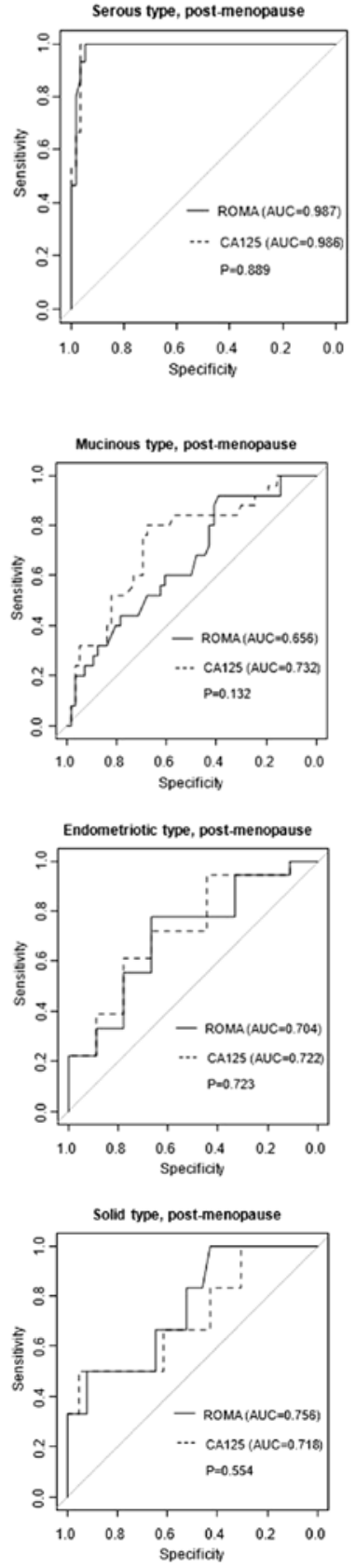

Figure 1. ROCs curve for ROMA test and CA125 for each tumor type in premenopausal and postmenopausal women. The solid line represents the result of the ROMA test and the dotted line represents the result of CA125. (A) ROC curve for all ovarian tumor types. (B) ROC curve for serous type ovarian tumor. (C) ROC curve for mucinous type ovarian tumor. (D) ROC curve for endometriotic type ovarian tumor. (E) ROC curve for solid type ovarian tumor. In general, an AUC of $\geq 0.7$ or higher is considered acceptable, while 0.8-0.9 is considered excellent. ROMA, Risk of Ovarian Malignancy Algorithm; CA125, cancer antigen 125; ROC, receiver operating characteristic; AUC, area under the curve.

The present study had certain limitations. First, it had a retrospective design and thus, it was not possible to identify any physical conditions that may have affected CA125 or HE4, including inflammation or smoking at the time of examination. Furthermore, the present study had the precondition that the type of ovarian tumor was able to be clearly distinguished through sonography or APCT. Most ovarian tumors can be accurately distinguished as specific tumor types via imaging tests prior to surgery. However, this is difficult in some tumors. It may be challenging to differentiate hemorrhagic corpus luteal cysts from endometriotic cysts. Finally, adenomyosis was a suspicious result during imaging; however, this was not histologically confirmed. However, if adenomyosis was sufficiently severe to affect CA125 levels, it should be detectable using ultrasound.

In conclusion, the present study compared the predictive value of CA125 and the ROMA test for differentiating ovarian tumors according to imaging tumor subtypes associated with post-operative histopathological findings. To the best of our knowledge, the present study was the first to analyze the discrimination performance of ROMA for ovarian tumors in each tumor subtype for patients undergoing surgery. In the endometriotic type ovarian tumor, the superiority of the ROMA test compared with CA125 was confirmed in the triage of ovarian tumor. However, these comparative advantages were not observed in the other tumor subtypes and post-menopausal females. Therefore, it was demonstrated that the ROMA test was more beneficial compared with the conventional CA125 as a triage biomarker, but only for endometriotic-type ovarian tumors as determined using imaging. Most benign ovarian tumors occur in women of childbearing age in their 20 to 40s with periodic ovulation; however, the frequency of malignancies is higher in ovarian tumors that develop after menopause (25). The present study reported that the ROMA test is not superior to CA125 in post-menopausal females. This highlights the requirement to develop better tumor-specific biomarkers, including circulating tumor DNA. In the future, it will be important to improve the accuracy and convenience of relevant tests to facilitate their clinical application.

\section{Acknowledgements}

Not applicable.

\section{Funding}

No funding was received.

\section{Availability of data and materials}

The datasets used and/or analyzed during the present study are available from the corresponding author on reasonable request.

\section{Authors' contributions}

YJL and YMK conceptualized and designed the study and drafted the initial manuscript. JSK, SHN and YJL collected the data, performed initial analyses and reviewed and revised the manuscript. DYK and YTK performed statistical analysis, 
interpreted the data, reviewed and revised the manuscript. All authors read and approved the final manuscript.

\section{Ethics approval and consent to participate}

This study was conducted in accordance with the Declaration of Helsinki. This study was approved by The Institutional Review Board of the Asan Medical Center of Ulsan University (approval no. 2019-0616).

\section{Patient consent for publication}

Not applicable.

\section{Competing interests}

The authors declare that they have no competing interests.

\section{References}

1. Siegel RL, Miller KD and Jemal A: Cancer statistics, 2016. CA Cancer J Clin 66: 7-30, 2016.

2. Bast RC, Feeney M, Lazarus H, Nadler LM, Colvin RB and Knapp RC: Reactivity of a monoclonal antibody with human ovarian carcinoma. J Clin Invest 68: 1331-1337, 1981.

3. Sevinc A, Adli M, Kalender ME and Camci C: Benign causes of increased serum CA-125 concentration. Lancet Oncol 8: 1054-1055, 2019

4. Medeiros LR, Rosa DD, da Rosa MI and Bozzetti MC: Accuracy of CA 125 in the diagnosis of ovarian tumors: A quantitative systematic review. Eur J Obstet Gynecol Reprod Biol 142: 99-105, 2019.

5. Engelen MJ, de Bruijn $\mathrm{HW}$, Hollema $\mathrm{H}$, ten Hoor KA, Willemse PH, Aalders JG and van der Zee AG: Serum CA 125 , carcinoembryonic antigen, and CA $19-9$ as tumor markers in borderline ovarian tumors. Gynecol Oncol 78: 16-20, 2019.

6. Simmons AR, Baggerly K and Bast RC: The emerging role of HE4 in the evaluation of epithelial ovarian and endometrial carcinomas. Oncology (Williston Park) 27: 548-556, 2019.

7. Lu R, Sun X, Xiao R, Zhou L, Gao X and Guo L: Human epididymis protein 4 (HE4) plays a key role in ovarian cancer cell adhesion and motility. Biochem Biophys Res Commun 419: 274-280, 2012.

8. Schummer M, Ng WV, Bumgarner RE, Nelson PS, Schummer B, Bednarski DW, Hassell L, Baldwin RL, Karlan BY and Hood L: Comparative hybridization of an array of 21,500 ovarian cDNAs for the discovery of genes overexpressed in ovarian carcinomas. Gene 238: 375-385, 1999.

9. Granato T, Porpora MG, Longo F, Angeloni A, Manganaro L and Anastasi E: HE4 in the differential diagnosis of ovarian masses. Clin Chim Acta 446: 147-155, 2015.

10. Hallamaa M, Suvitie P, Huhtinen K, Matomäki J, Poutanen M and Perheentupa A: Serum HE4 concentration is not dependent on menstrual cycle or hormonal treatment among endometriosis patients and healthy premenopausal women. Gynecol Oncol 125: 667-672, 2012.

11. Moore RG, Miller MC, Eklund EE, Lu H, Bast RC and Lambert-Messerlian G: Serum levels of the ovarian cancer biomarker HE4 are decreased in pregnancy and increase with age. Am J Obstet Gynecol 206: 349.e1-349.e7, 2012.
12. Moore RG, McMeekin DS, Brown AK, DiSilvestro P, Miller MC, Allard WJ, Gajewski W, Kurman R, Bast RC Jr and Skates SJ: A novel multiple marker bioassay utilizing HE4 and CA125 for the prediction of ovarian cancer in patients with a pelvic mass. Gynecol Oncol 112: 40-46, 2009.

13. Moore RG, Miller MC, Disilvestro P, Landrum LM, Gajewski W, Ball JJ and Skates SJ: Evaluation of the diagnostic accuracy of the risk of ovarian malignancy algorithm in women with a pelvic mass. Obstet Gynecol 118: 280-288, 2011.

14. Drapkin R, von Horsten HH, Lin Y, Mok SC, Crum CP, Welch WR and Hecht JL: Human epididymis protein 4 (HE4) is a secreted glycoprotein that is overexpressed by serous and endometrioid ovarian carcinomas. Cancer Res 65: 2162-2169, 2005.

15. Kim B, Park Y, Kim B, Ahn HJ, Lee KA, Chung JE and Han SW: Diagnostic performance of CA 125, HE4, and risk of Ovarian Malignancy Algorithm for ovarian cancer. J Clin Lab Anal 33: e22624, 2019.

16. Molina R, Escudero JM, Augé JM, Filella X, Foj L, Torné A, Lejarcegui J and Pahisa J: HE4 a novel tumour marker for ovarian cancer: Comparison with CA 125 and ROMA algorithm in patients with gynaecological diseases. Tumor Biol 32: 1087-1095, 2011.

17. Romeo V, Framarino Dei Malatesta M, Nudo F, Simonelli L, Derme M and Berloco PB: Is HE4 serum level a valid screening test in women candidates for kidney transplant? A case report and a review of literature. Clin Ter 165: e162-e165, 2014.

18. Anton C, Carvalho FM, Oliveira EI, Maciel GAR, Baracat EC and Carvalho JP: A comparison of CA125, HE4, risk ovarian malignancy algorithm (ROMA), and risk malignancy index (RMI) for the classification of ovarian masses. Clinics (Sao Paulo) 67: 437-441, 2012.

19. Mutch DG and Prat J: 2014 FIGO staging for ovarian, fallopian tube and peritoneal cancer. Gynecol Oncol 133: 401-404, 2014.

20. Ruggeri G, Bandiera E, Zanotti L, Belloli S, Ravaggi A, Romani C, Bignotti E, Tassi RA, Tognon G, Galli C, et al: HE4 and epithelial ovarian cancer: Comparison and clinical evaluation of two immunoassays and a combination algorithm. Clin Chim Acta 412: 1447-1453, 2011.

21. Lenhard M, Stieber P, Hertlein L, Kirschenhofer A, Fürst S, Mayr D, Nagel D, Hofmann K, Krocker K and Burges A: The diagnostic accuracy of two human epididymis protein 4 (HE4) testing systems in combination with CA125 in the differential diagnosis of ovarian masses. Clin Chem Lab Med 49: 2081-2088, 2011.

22. Chan KK, Chen CA, Nam JH, Ochiai K, Wilailak S, Choon AT, Sabaratnam S, Hebbar S, Sickan J, Schodin BA and Sumpaico WW: The use of HE4 in the prediction of ovarian cancer in Asian women with a pelvic mass. Gynecol Oncol 128: 239-244, 2019

23. Karlsen MA, Høgdall EV, Christensen IJ, Borgfeldt C, Kalapotharakos G, Zdrazilova-Dubska L, Chovanec J, Lok CA, Stiekema A, Mutz-Dehbalaie I, et al: A novel diagnostic index combining HE4, CA125 and age may improve triage of women with suspected ovarian cancer-An international multicenter study in women with an ovarian mass. Gynecol Oncol 138: 640-646, 2015.

24. Dayyani F, Uhlig S, Colson B, Simon K, Rolny V, Morgenstern D and Schlumbrecht M: Diagnostic performance of risk of ovarian malignancy algorithm against CA125 and HE4 in connection with ovarian cancer: A Meta-analysis. Int J Gynecol Cancer 26: 1586-1593, 2019.

25. Wolman I: Berek and Novak's Gynecology 15th Edition. J Obstet Gynecol India 2014. 